\title{
Comparative Analysis of Chinese and Western Authors' Use of Evidentiality
}

\author{
Tian Dong ${ }^{1 *}$, Shaoan Zhang ${ }^{2}$, Lu Qiu ${ }^{1}$, Steven McCafferty ${ }^{2}$ \\ ${ }^{1}$ North China Electric Power University Baoding, Hebei, China \\ ${ }^{2}$ University of Nevada, Las Vegas
}

DOI: $10.36348 /$ sijll.2019.v02i07.004

| Received: 21.09.2019 | Accepted: 28.09.2019 | Published: 30.09.2019

*Corresponding author: Tian Dong

\section{Abstract}

Academic writing is the process of authors' interaction and communication with readers. Based on Yang's classification of evidentiality and self-built corpus, this study examines and compares the characteristics of Chinese and western authors' use of evidentiality in second language academic writing. The major results include: 1) Evidentials are universal in research papers. Chinese authors' less use of evidentials indicates their tendency to conceal personal opinions to offer more objective arguments; 2) Both Chinese and western authors prefer reporting and inferring evidentials, owing to the style of natural science and the language practice of the subject; 3) The frequency of English authors' sensory and belief evidentials is significantly higher than that of Chinese authors due to the different cultural backgrounds; and 4) As to the specific realization of each evidential type, the commonality and difference coexist.

Keywords: Evidentiality; Evidential; Chinese Authors; Western authors.

Copyright @ 2019: This is an open-access article distributed under the terms of the Creative Commons Attribution license which permits unrestricted use, distribution, and reproduction in any medium for non-commercial use (NonCommercial, or CC-BY-NC) provided the original author and source are credited.

\section{INTRODUCTION}

Early in 1911 Franz Boas first discovered a grammatical form in American Indian's Kwakiutl that can indicate the source of information and a certain degree of propositions, the language phenomenon of evidentiality. The research in evidentiality has aroused great interest of scholars. Boas officially introduced Evidentiality to the field of linguistic research in 1947 and his publication in 1986 established a strong position of evidentiality in the field of linguistics [5].

As source of information and author's commitment to the factual situation of propositions, evidentiality is widely used in the terminology [21-23]. In various academic discourses, research papers are viewed to be the most important means of academic communication [24]. Thus academic writing is considered to be objective rather than subjective, which implies that the infiltration of personal attitude should be refrained. However, academic writing is actually an academic interaction and communication between authors and readers [24]. The author may promote his position and build his identity through communicating with readers using a variety of linguistic resources and rhetorical means in order to attract readers to participate in the discourse, for instance, self-mentions and evidentiality. English terminology contains a wealth of evidentials [4]. But evidentiality of second-language academic writing has not caused enough attention [20]. The exploration of evidentiality potentially contributes to the research in academic writing in different fields. Unfortunately, the existent literature is scarce [11]. Using linguistic statistics, this paper examines the characteristics of evidentiality used by Chinese and western scholars.

However, at present, there are still many limitations in the research on evidentiality at home and abroad. Firstly, the research subjects mainly focus on the humanities and social sciences, and rarely investigate the science and engineering disciplines. Secondly, the research direction is usually around the comparison between languages, such as the difference of evidentials between English and Chinese texts rather than the difference of writers in the same language. Even the researcher takes writers in the same language as subject, they often choose the subjects with different educational degrees, such as experts and students, undergraduates, masters and doctors. The writers with similar educational or linguistic level but different cultural background or nationalities are seldom involved. In other words, the theme of cultural 
differences, which is the most concerned in the frontier of international academic English writing [14], has not been taken much into consideration when studying evidentiality. Therefore, this paper takes this as the breakthrough point and selects the English Engineering articles respectively written by Chinese and western authors' as research objects.

\section{LITERATURE REVIEW CONCEPTS OF EVIDENTIALITY}

AND

Scholars have not reached an agreement on its definition from the time when Boas created the term. From the broad sense, evidentiality refers to the speaker's attitude towards what he says, not only explaining the information source, but also expressing his attitude and commitment to the knowledge given [4]. Aikhenvald [2] notes that the semantics of evidentiality should be centered on the information source. Fang [6] further explains that evidentiality means the speaker's explanation about the source and reliability of proposition or information by means of language coding. Yang argues that the narrow definition represented by Aikhenvald may not work for English language research [21].

The semantics of evidentiality is pervasive but its expressions are language-specific. Willet [17] divides type of evidence into direct and indirect in its narrow sense. Chafe and Nichols [4] adopts a broader classification which covers source of information, mode of information, reliability of knowledge and knowledge matched against. Aikhenvald [3] divides evidentiality into two categories: eyewitness and non-eyewitness. Based on their classifications, Yang [21] classifies evidentiality into four categories: sensory evidentials, reporting evidentials (self-reporting and otherreporting), inferring evidentials, and belief evidentials.

$\mathrm{Hu}$ [9] introduced the research development and representative scholars in linguistic circle including Chafe [4], Anderson [1] and Willett [17] in the 1980s. Fang [7] provided a comprehensive review of the definition, classification, characteristics and research perspective of evidentiality. Yang [21] analyzed the status quo of domestic evidentiality research, and suggested development direction toward multitheoretical, multi-discourse and interdisciplinary research. Xu and Gong [19] found that students significantly used more sensory and reporting evidentials and less belief and inferring evidentials, indicating a tendency to rely excessively on other voices to express their opinions. Yu [23] conducted a statistical analysis of the corpus of doctoral dissertation in four disciplines including linguistics, computer science, medicine and economics, and found that sensory, reporting, belief and inferring evidentials were all used, in which the frequency of belief evidentials is quite low. As far as the related topics are concerned, the evidentials in political discourse and news discourse have also received more and more attention in recent years. The research of Wang and Liu [15] found that New York Times prefers indirect inferring evidentials and modal strategies, while People's Daily tends to use indirect reporting evidentials and cognitive attitude predicates. Ran and Liu's [12] paper showed that evidentials modify the illocutionary act and influence the effect of speech. Using evidentials with high degree of credibility and involvement, such as memory and sensory evidentials, can create a credible image for the candidate, and shorten the distance between the audience and the candidate. And the excessive use of belief evidentials with low-confidence will inevitably cause doubts from the audience.

In addition to the educational background and disciplinary differences, the difference in the way evidentials are used lies in the cultural background and the degree of mastery of interpersonal meaning. Wang [16] compared the characteristics of evidentials usage in 90 Chinese and American master's theses in empirical linguistics and concluded that: (1) the distribution of evidentials is consistent and unbalanced; (2) the research method will affect the use of sensory evidentials and inferring evidentials; (3) Chinese masters significantly use more sensory evidentials and less inferring and reporting evidentials, showing a "reader-responsible" Chinese discourse model. Zhao [24] found that English authors are good at using various evidentials to guide readers to interpret discourse and try to present the identity of discourse constructor. Regarding discourse as an objective statement of knowledge, Chinese authors stress the reliability of information, tend to enumerate predecessors' research and avoid personal attitudes by showing their identity. Guan [8] examined the distribution of evidentials in 60 core journals of applied linguistics by Chinese and western scholars, and found that Chinese authors pay attention to the construction of discoursal self as self-representation projected in the text, while western authors place more emphases on authorial self which denotes the writer's own voice.

From the domestic and foreign research, we can see that scholars have begun to attach importance to evidentiality in academic English papers from different disciplines and educational backgrounds. But the total amount of publications on the topic of evidentiality is still quite small. Therefore, it is a virgin land to be developed.

\section{RESEARCH DESIGN \\ Research Questions}

The purpose of this study is to analyze the characteristics and differences in the use of evidentials in Chinese and western authors' research articles, focusing on the following two interrelated aspects:

- The overall distribution characteristics of evidentials in Chinese and western authors' research papers and examination of the similarity and difference. 
- The examination of specific lexical and grammatical forms of different evidential types.

Four types of evidentials are explained here. Sensory evidentials indicate that the proposition information comes from firsthand experience, so they have a high degree of credibility and are more easily accepted by readers. The way to obtain sensory evidentials includes a variety of sensory channels such as tables, figures, examples, etc. Most sensory evidentials are presented by the verb see or its passive form seen. Reporting evidentials are divided into selfreporting and other-reporting evidentials in terms of information source. Self-reporting means that the information comes from the writer himself and the source related to the research article, for instance, $I$, we, our, my, our analysis, our research, this article. The authors use self-reporting to promote their research claims, findings and results. Other-reporting indicates that the information is derived from external resources rather than the speaker, typically the cited authors, their experiments, data, results, and the unknown resources. Belief evidentials indicate that the information comes from the author's opinion and attitude towards the proposition, which can be the subjective we suppose, we assume, I argue, etc., or some objective phrases like it should be noted that. Inferring evidentials in scientific research papers represents the possibility and probability of an argument based on hypothesis and reasoning. They are mainly embodied by modal verbs, relational process in transitivity, adjectives and modal adjuncts in the lexical grammar layer. By choosing modal verbs of different value, the writer will take different responsibility for the information given. Words with high degree of modal values such as must, certain, obviously, indicate higher certainty and responsibility of the author to the statements while low degree of modal values such as might, possible, and like, can lessen author's commitment for presenting information.

\section{Corpus Collection}

This research self-built Chinese and western scholars' corpus, selected the number of 100 scientific research papers from the internationally recognized journal SCI in the power professional ( 50 are written by Chinese authors and 50 by English authors). All western authors followed Wood's [18] definition of native speakers: the first author's name is a common name of British and American native speakers, and the first language of the country where the undersigned unit is located is English. Similarly, all Chinese scholars were selected by: the first author's name is a common name in China represented by Pinyin, and the signature unit is located in mainland China. At the same time, in order to ensure the timeliness of language, the publication time of these papers is in the period of
2015-2018. Then, the corpus was arranged according to the first author's country, for example, Chinese author's papers are labeled as $\mathrm{C}-1, \mathrm{C}-2 \ldots$, and the western author's papers are arranged as $\mathrm{W}-1, \mathrm{~W}-2 \ldots$. Next, other parts such as the title, author information, chart name, chart content, acknowledgment, and references are removed, so only the body part was used for analysis corpus.

\section{Analysis Procedures}

Adopting the qualitative method, this study was divided into two phases. In the first phase, based on Yang's [21] classification of evidentiality, evidentials were organized into four types: sensory evidential, inferring evidential, reporting evidential and belief evidential. In the second phase, considering the practical situation of each evidential type in the target corpus, the evidentials were screened and manually identified. Then, with the help of the searching tool Ant Conc3.5.0 combined with manual troubleshooting, all evidentials were retrieved and counted. Log-likelihood test was performed to see if there was a significant difference according to the significance value. The difference exists only when the value is lower than 0.05 . If the value is lower than 0.01 , it means there is significant or strong significance between the two subjects.

It should be noted that when two evidentials occurred at the same time, they were divided according to the specific context, only counting once. For example, both the referring evidential can in the form of modal verb and the reporting evidential found in the form of passive reporting verb appeared in the sentence "A variety of strategies for controlling DER in distribution systems can be found in literature". Since the focus of this case falls on the research findings of literature, the two evidentials are classified as reporting evidential which found here belongs to.

\section{RESULTS AND DISCUSSION}

In this section, the overall distribution of all evidentials are first presented. Then followed by the detailed forms of each evidential type. Sensory evidentials are comprised of see and seen. The three forms of reporting evidentials are parentheses, verbal and non-verbal. Inferring evidentials can be divided into modal verb, relational process, adjectives and modal adjunct. The typical belief evidential is we suppose/think or it suggests, which is embodied by the first person pronouns and the formal subject it.

In all the tables of the finding report, Sig is an abbreviation for significance. When Sig $<0.05$, it indicates that there is a significant difference; when $\mathrm{Sig}$ $<0.01$, it has a higher level of significant difference. 


\section{Comparative Analysis of Evidentiality in Chinese and Western Corpus}

Table-1: Realization of evidentials in Chinese and western corpus

\begin{tabular}{|c|c|c|c|c|c|}
\hline \multirow{2}{*}{ Type } & \multicolumn{2}{|c|}{ Chinese Author } & \multicolumn{2}{c|}{ Western Author } & \multirow{2}{*}{$\boldsymbol{i}$} \\
\cline { 2 - 5 } & Frequency & Percent & Frequency & Percent & $\boldsymbol{g}$ \\
\hline Sensory & 188 & $2.65 \%$ & 251 & $3.08 \%$ & 0.006 \\
\hline Reporting & 4139 & $58.43 \%$ & 4896 & $60.10 \%$ & 0.000 \\
\hline Inferring & 2703 & $38.16 \%$ & 2875 & $35.29 \%$ & 0.158 \\
\hline Belief & 54 & $0.76 \%$ & 124 & $1.52 \%$ & 0.000 \\
\hline Total & 7084 & $100 \%$ & 8146 & $100 \%$ & 0.006 \\
\hline
\end{tabular}

Table-1 shows that Chinese and western authors used evidentials when writing scientific research papers, and all four evidential types are included. Except inferring evidentials, the other three evidential patterns are significantly different. It implies that even in scientific articles that speak with objective data, evidentiality are quite universal, which is consistent with the findings of recent studies [10, 23].

The total number of evidentials is similar, appearing 7,084 and 8,146 times respectively. Among them, the frequency of reporting evidentials rank the highest with 4,139 and 4,896 times, which accounts for $58.43 \%$ and $60.10 \%$ respectively. Inferring evidentials, which occur 2,703 and 2,875 times respectively, accounting for $38.22 \%$ and $35.53 \%$, and bear a much higher frequency than sensory evidentials with the percentage of $2.65 \%$ and $3.08 \%$. Unlike the former three evidentials, belief evidentials are less common in research papers. It amounts to $0.76 \%$ in Chinese authors' articles, and the proportion of English authors is $1.52 \%$.

We conclude that western authors used evidentials more frequently than Chinese authors, suggesting that English authors pay more attention to information source. In order to make the paper more objective, Chinese authors tend to avoid explicit information source no matter whether it is from other or their own sources. The same order of four types of evidentials indicate a consistency and imbalance of distribution. This finding confirms Wang's [16] research that both the Chinese and western authors have mastered the writing norms of academic papers and can grasp the characteristics of objectivity and rigor, and the purpose of transmitting academic information.

\section{Distribution Characteristics of Sensory Evidentials}

Table-2: Distribution of sensory evidentials in Chinese and western corpus

\begin{tabular}{|c|c|c|c|c|c|}
\hline \multirow{2}{*}{ Type } & \multicolumn{2}{|c|}{ Chinese Author } & \multicolumn{2}{|c|}{ Western Author } & \multirow{2}{*}{ Sig } \\
\cline { 2 - 5 } & Frequency & Percent & Frequency & Percent & \\
\hline see & 45 & $23.94 \%$ & 168 & $66.93 \%$ & 0.000 \\
\hline Be+ seen & 143 & $76.06 \%$ & 83 & $33.07 \%$ & 0.000 \\
\hline Total & 188 & $100 \%$ & 251 & $100 \%$ & 0.006 \\
\hline
\end{tabular}

Table-2 shows that western and Chinese authors have significant differences in the application of sensory evidentials. Chinese authors used passive tense a lot, 143 times, reaching 76.06\%, while English authors used active tense more frequently, 168 times, accounting for $66.93 \%$. This result shows that Chinese authors often turn to objective and abstract charts or tables so that research results can be seen, while western authors attach more importance to interact with readers, and lead readers to interact through intuitive see.

\section{Distribution Characteristics of Reporting Evidentials}

In the specific language form, reporting evidentials are mainly achieved in three ways: parenthetical references, verbal, and non-verbal. In terms of information source, reporting evidentials are divided into self-reporting and other-reporting evidentials. The authors use self-reporting to promote their research claims, findings and results. Otherreporting indicates that the information is derived from external resources rather than the speaker, typically the cited authors, their experiments, data, results, and the unknown resources.

Table-3: Distribution of reporting evidentials in Chinese and western corpus

\begin{tabular}{|c|c|c|c|c|c|}
\hline \multirow{2}{*}{ Type } & \multicolumn{2}{|c|}{ Chinese Author } & \multicolumn{2}{|c|}{ Western Author } & \multirow{2}{*}{ Sig } \\
\cline { 2 - 5 } & Frequency & Percent & Frequency & Percent & \\
\hline parentheses & 1238 & $29.93 \%$ & 1714 & $35.01 \%$ & 0.000 \\
\hline verbal & 2848 & $68.87 \%$ & 3057 & $62.44 \%$ & 0.071 \\
\hline non-verbal & 50 & $1.21 \%$ & 125 & $2.55 \%$ & 0.000 \\
\hline Total & 4137 & $100 \%$ & 4896 & $100 \%$ & 0.000 \\
\hline
\end{tabular}


Table-3 shows that the percentage of verbal reporting evidentials ranks the highest, with $68.87 \%$ and $62.44 \%$, nearly two-thirds without a significant difference. Parenthetical references is followed, so Chinese authors used 1238 times, and English authors used 1714 times, accounting for $29.93 \%$ and $35.01 \%$ respectively, with a significant difference. The nonverbal form ranks lowest, with 50 and 125 appearances with the percentage of $1.21 \%$ and $2.55 \%$ respectively. However, the frequency of western authors is still twice more than that of Chinese authors. Reporting evidentials in the form of verbal or non-verbal have similar expression meaning, but Chinese authors' nonverbal form is used much less frequently, suggesting that their ability to use non-verbal reporting evidentials differs.

Table-4: Distribution of verbal reporting evidentials in Chinese and western corpus ranking 1-10

\begin{tabular}{|c|c|c|c|c|c|c|}
\hline & \multicolumn{3}{|c}{ Chinese Author } & \multicolumn{3}{c|}{ Western Author } \\
\hline Rank & Verb & Frequency & Percent & Verb & Frequency & Percent \\
\hline 1 & shown & 642 & $22.54 \%$ & shown & 567 & $18.55 \%$ \\
\hline 2 & propose & 512 & $17.98 \%$ & show & 348 & $11.38 \%$ \\
\hline 3 & show & 274 & $9.62 \%$ & propose & 301 & $9.85 \%$ \\
\hline 4 & according to & 221 & $7.76 \%$ & consider & 226 & $7.39 \%$ \\
\hline 5 & consider & 166 & $5.83 \%$ & describe & 200 & $6.54 \%$ \\
\hline 6 & indicate & 134 & $4.71 \%$ & note & 158 & $5.17 \%$ \\
\hline 7 & illustrate & 91 & $3.20 \%$ & found & 135 & $4.42 \%$ \\
\hline 8 & observe & 88 & $3.09 \%$ & indicate & 133 & $4.35 \%$ \\
\hline 9 & found & 81 & $2.84 \%$ & demonstrate & 131 & $4.29 \%$ \\
\hline 10 & demonstrate & 76 & $2.67 \%$ & observe & 126 & $4.12 \%$ \\
\hline Total & & 2285 & $80.24 \%$ & & 2325 & $76.06 \%$ \\
\hline
\end{tabular}

Table-5: Distribution of verbal reporting evidentials in western corpus ranking 11-20

\begin{tabular}{|c|c|c|c|c|c|c|}
\hline & \multicolumn{3}{|c|}{ Chinese Author } & \multicolumn{3}{c|}{ Western Author } \\
\hline Rank & Verb & Frequency & Percent & Verb & Frequency & Percent \\
\hline 11 & describe & 69 & $2.42 \%$ & discuss & 123 & $4.02 \%$ \\
\hline 12 & discuss & 64 & $2.25 \%$ & illustrate & 118 & $3.86 \%$ \\
\hline 13 & maintain & 52 & $1.83 \%$ & according to & 87 & $2.85 \%$ \\
\hline 14 & mention & 47 & $1.65 \%$ & maintain & 61 & $2.00 \%$ \\
\hline 15 & conclude & 32 & $1.12 \%$ & find & 38 & $1.24 \%$ \\
\hline 16 & explain & 31 & $1.09 \%$ & suggest & 37 & $1.21 \%$ \\
\hline 17 & put & 31 & $1.09 \%$ & explain & 36 & $1.18 \%$ \\
\hline 18 & reveal & 29 & $1.02 \%$ & report & 33 & $1.08 \%$ \\
\hline 19 & report & 28 & $0.98 \%$ & summarize & 32 & $1.05 \%$ \\
\hline 20 & accordingly & 27 & $0.95 \%$ & reveal & 23 & $0.75 \%$ \\
\hline Total & & 410 & $14.40 \%$ & & 588 & $19.24 \%$ \\
\hline
\end{tabular}

Of 42 kinds of reporting verbs in the two corpuses, 35 appeared in Chinese corpus and 40 in western corpus. English authors show a higher richness of verb types with 5 more than Chinese authors. In addition, western authors rarely used accordingly that Chinese authors used frequently.

Among these reporting verbs, common highfrequency ones include shown, propose, show and consider. The verb show and particularly its passive form, shown, are the most frequently used by Chinese and western authors. Shown, propose, show in Chinese corpus appeared 642 times, 512 times and 274 times respectively, accounting for $22.54 \%, 17.98 \%$ and $9.62 \%$ of frequency. These three words take up half of the frequency of 1428 times with $50.14 \%$. In comparison, the order of top three verbs are shown, show and propose in western articles. Their frequency are 567, 348 and 301 times, 1216 times in total, accounting for $18.55 \%, 11.38 \%$ and $9.85 \%$ respectively and $39.78 \%$ in sum. The total proportion of western authors is significantly lower than that of Chinese authors.

Ranking the fourth and fifth in Chinese corpus are according to and consider, while the evidentials, consider and describe are in western corpus. Chinese authors used according to 221 times, accounting for $7.76 \%$, while English authors only used 87 times, accounting for $2.85 \%$. Describe is used 200 times by western authors, accounting for $6.54 \%$ but merely 69 times by Chinese authors, accounting for $2.42 \%$. In the choice of specific reporting verbs, Chinese and western authors have different preference. The top ten verbs of Chinese authors have a total frequency of 2285 , accounting for $80.24 \%$. The top ten of western authors appeared 2,325 times with $76.06 \%$. Although the number of western authors' top ten reporting verbs is larger than that of Chinese authors, the total proportion is lower. It reveals that English authors distribute 
reporting verbs more widely, highlighting the diversity of forms, while Chinese authors only use certain reporting verbs that they are more familiar with, and have a lower awareness of variety.
Distribution Characteristics of Belief Evidentials

In the 100 journal articles of this study, there are totally 23 language forms of belief evidentials.

Table-6: Distribution of belief evidentials in Chinese corpus

\begin{tabular}{|c|l|l|l|}
\hline Rank & Type & Frequency & Percent \\
\hline 1 & we suppose & 18 & $35.29 \%$ \\
\hline 2 & it should be noted that & 13 & $25.49 \%$ \\
\hline 3 & we assume & 6 & $11.76 \%$ \\
\hline 4 & It can be tentatively suggested & 5 & $9.80 \%$ \\
\hline 5 & I/we suggest & 2 & $3.92 \%$ \\
\hline 6 & we consider & 2 & $3.92 \%$ \\
\hline 7 & It (can/may/will) be suggested & 1 & $1.96 \%$ \\
\hline 7 & It could be reasonable to recognize & 1 & $1.96 \%$ \\
\hline 7 & To the author's knowledge & 1 & $1.96 \%$ \\
\hline 7 & we believe & 1 & $1.96 \%$ \\
\hline 7 & we must ensure & 1 & $1.96 \%$ \\
\hline Total & & 51 & $100 \%$ \\
\hline
\end{tabular}

Table-7: Distribution of belief evidentials in western corpus

\begin{tabular}{|c|l|l|l|}
\hline Rank & Type & Frequency & Percent \\
\hline 1 & we assume & 33 & $27.05 \%$ \\
\hline 2 & we consider & 22 & $18.03 \%$ \\
\hline 3 & it should be noted that & 18 & $14.75 \%$ \\
\hline 4 & we refer to & 9 & $7.38 \%$ \\
\hline 5 & I argue & 8 & $6.56 \%$ \\
\hline 6 & we suppose & 6 & $4.92 \%$ \\
\hline 7 & to our knowledge & 5 & $4.10 \%$ \\
\hline 8 & we must bear in mind & 4 & $3.28 \%$ \\
\hline 9 & we believe & 3 & $2.46 \%$ \\
\hline 9 & we will assume & 3 & $2.46 \%$ \\
\hline 10 & we acknowledge & 2 & $1.64 \%$ \\
\hline 10 & we would expect & 2 & $1.64 \%$ \\
\hline 11 & It (can/may/will) be suggested & 1 & $0.82 \%$ \\
\hline 11 & we must ensure & 1 & $0.82 \%$ \\
\hline 11 & It (can/may/will) be argued & 1 & $0.82 \%$ \\
\hline 11 & It could be reasonable to suggest & 1 & $0.82 \%$ \\
\hline 11 & we will consider & 1 & $0.82 \%$ \\
\hline 11 & we wish to & 1 & $0.82 \%$ \\
\hline 11 & we suggest & 1 & $0.82 \%$ \\
\hline Total & & 122 & $100 \%$ \\
\hline
\end{tabular}

From Table-7 we see that western authors used belief evidentials 122 times, the frequency of which is almost 2.5 times than that of Chinese authors with only 51 times. This finding shows that English authors freely express their own opinions and attitudes, while Chinese authors try to avoid expressing attitudes so as to reduce the possible doubts caused by subjectiveness, which is consistent with Wang's study [16].

This diverse characteristics of Chinese and western authors in the use of belief evidentials reflect the differences between English and Chinese academic culture. In English culture, researchers seem to pay more attention to their own personality and try their best to personalize their writing. On the contrary, Chinese writers tend to hide personal identity and express results with objective data. The reason may be that the Chinese culture advocating humility and comity influence researchers' positioning their evidentials or use of evidentials and that not using belief evidentials may indicate their objective professional identity.

As to the specific grammatical form, English authors used a variety of grammatical forms with 19 kinds of evidentials, while Chinese papers were relatively poorly expressed with only 11 kinds, quite concentrated. The top two are we suppose and it should be noted that with a total of 31 times, accounting for $35.29 \%$ and $25.49 \%$ respectively and constituting $60.78 \%$ in total, while the top two of western authors are we assume and we consider, occurring 33 times and 22 times with the percent of $27.05 \%$ and $18.08 \%$ 
respectively. The total proportion of the two is $45.15 \%$, less than half, significantly lower than the top two of Chinese authors. What's notable is that the most frequently used we assume by English authors just occurs 6 times in Chinese authors' articles. While we suppose, prominent in Chinese corpus, only appeared 6 times in English authors' research articles, accounting for $4.92 \%$. The basic meanings of suppose and assume are both "hypothesis, guess", highly similar to each other. This reflects the different preferences for synonyms and suggests that it is important to distinguish synonyms in learning academic writing.

\section{Distribution Characteristics of Inferring Evidentials} Inferring evidentials cover speculative evidentials and hypothetical evidentials. Speculative evidentials include induction, deduction and the inferring processes based on vision and touch. Hypothetical evidentials focus on the inferring processes from logical reasoning, imagination and common sense [21].

Table-8: Distribution of inferring evidentials in Chinese and western corpus

\begin{tabular}{|l|c|c|c|c|c|}
\hline \multirow{2}{*}{ Type } & \multicolumn{2}{|c|}{ Chinese Author } & \multicolumn{2}{c|}{ Western Author } & \multirow{2}{*}{ Sig } \\
\cline { 2 - 5 } & Frequency & Percent & Frequency & Percent & \\
\hline Modal verb & 2498 & $92.42 \%$ & 2514 & $87.44 \%$ & 0.537 \\
\hline relational process & 1 & $0.04 \%$ & 7 & $0.24 \%$ & 0.027 \\
\hline adjectives & 146 & $5.40 \%$ & 316 & $10.99 \%$ & 0.000 \\
\hline Modal adjunct & 58 & $2.15 \%$ & 38 & $1.32 \%$ & 0.030 \\
\hline Total & 2703 & $100 \%$ & 2875 & $100 \%$ & 0.000 \\
\hline
\end{tabular}

As shown in Table-8, in general, the frequency of inferring evidentials used by Chinese authors is 2,703 times, and the number of western authors is 2,875 times. The overall frequency of Chinese authors is significantly lower than that of English authors.

From the horizontal perspective, the four grammatical types of inferring evidentials are all applied. Among them, modal verbs take the predominant place, accounting for $92.42 \%$ and $87.44 \%$ respectively without a significant difference. It implies that Chinese and western authors highly correspond with each other.

The second is adjectives. Chinese authors used adjectives 146 times, accounting for $5.40 \%$, while English authors used 316 times at $10.99 \%$, which was twice as many as that of Chinese authors. The significance value, $\mathrm{p}<0.01$, indicating a very high degree of difference. It implies that Chinese authors rely much on modal verbs and has not grasped the use of adjectives [13].

The third is modal adjuncts, occurring 58 and 38 times, accounting for $2.15 \%$ and $1.32 \%$ respectively. Chinese authors used more modal adjuncts and less adjectives than western authors. This shows a great different preference in eastern and western choice of inferring evidential type. Chinese authors use modal verbs, while English authors choose adjectives. One of the reasons may be that Chinese authors have a good command of verb-object structure, so inferring evidentials are often inserted through adverbs/modal adjuncts. In comparison, Western authors used more varied sentence patterns, especially various kinds of clauses, so inferring evidentials of adjectives are used more.

Table-9: Distribution of modal verbs in Chinese and western corpus

\begin{tabular}{|c|c|c|c|c|c|c|c|}
\hline \multirow[t]{2}{*}{ Type } & & \multicolumn{3}{|c|}{ Chinese Author } & \multicolumn{3}{|c|}{ Western Author } \\
\hline & Rank & & Frequency & Percent & & Frequency & Percent \\
\hline \multirow{8}{*}{ Modal verbs } & 1 & can & 1365 & $54.64 \%$ & can & 1009 & $40.14 \%$ \\
\hline & 2 & will & 454 & $18.17 \%$ & will & 500 & $19.89 \%$ \\
\hline & 3 & may & 213 & $8.53 \%$ & may & 292 & $11.61 \%$ \\
\hline & 4 & should & 164 & $6.57 \%$ & would & 213 & $8.47 \%$ \\
\hline & 5 & could & 152 & $6.08 \%$ & must & 179 & $7.12 \%$ \\
\hline & 6 & would & 106 & $4.24 \%$ & could & 176 & $7.00 \%$ \\
\hline & 7 & must & 26 & $1.04 \%$ & should & 107 & $4.26 \%$ \\
\hline & 8 & might & 18 & $0.72 \%$ & might & 38 & $1.51 \%$ \\
\hline Total & & & 2498 & $100 \%$ & & 2514 & $100 \%$ \\
\hline
\end{tabular}

From the vertical perspective, in the eight inferring modal verbs, the top three are the same, can, will and may, and the least used is might, which reveals the consistency of Chinese and western authors.
Two points are worth noting. One is the use of should, which ranks fourth in Chinese corpus with 164 times, but 104 times in Western corpus ranking at the seventh place. Chinese authors are more inclined to choose should, which contains the meaning of 
persuasion. In contrast, English authors like must more, with the frequency of 179 times and the percentage of $7.12 \%$, while Chinese authors used it very few with only 26 times and $1.04 \%$. This result is contrary with Wang's finding [16], which may be caused by the different disciplines. The evidential, Must has a high degree of certainty so that English authors highlight their professionalism and authority through the use of must. The second is would, which Chinese author only used 106 times, while western authors used 213 times, twice as many as Chinese authors. Relational process is used just one time in Chinese research papers and 36 times by western authors including appear to 21 times and seek to 15 times.

Table-10: Distribution of adjectives in Chinese and western corpus

\begin{tabular}{|c|c|c|c|c|c|c|c|}
\hline \multirow[t]{2}{*}{ Type } & & \multicolumn{3}{|c|}{ Chinese Author } & \multicolumn{3}{|c|}{ Western Author } \\
\hline & Rank & & Frequency & Percent & & Frequency & Percent \\
\hline \multirow{8}{*}{ adjectives } & 1 & certain & 77 & $85.56 \%$ & certain & 140 & $44.30 \%$ \\
\hline & 2 & possible & 36 & $24.66 \%$ & clear & 59 & $18.67 \%$ \\
\hline & 3 & clear & 19 & $13.01 \%$ & possible & 55 & $17.41 \%$ \\
\hline & 4 & likely & 9 & $6.16 \%$ & noticeable & 47 & $14.87 \%$ \\
\hline & 5 & evident & 4 & $2.74 \%$ & unclear & 8 & $2.53 \%$ \\
\hline & 6 & noticeable & 1 & $0.68 \%$ & likely & 4 & $1.27 \%$ \\
\hline & 7 & unclear & l & l & evident & 2 & $0.63 \%$ \\
\hline & 8 & probable & 1 & 1 & probable & 1 & $0.32 \%$ \\
\hline Total & & & 146 & $100 \%$ & & 316 & $100 \%$ \\
\hline
\end{tabular}

As to adjectives, certain, possible, and clear are ranked to be the top three. The difference lies in that Chinese authors used clear more than possible, but English authors are the opposite. Chinese authors prefer ambiguous words in order to leave room for further discussion, while English authors behave more confident with the use of must and clear. In Chinese corpus, the adjectives ranking the fourth, fifth, and sixth are likely, evident and noticeable while they are noticeable, unclear, and likely in western corpus. English authors pay more attention to the adjective noticeable with 47 times and $14.87 \%$, which is easy to arouse reader's attention. On the whole, Chinese authors tend to choose inferring evidentials of low modality, and their vocabulary type is less rich than that of English authors.

\section{CONCLUSION}

As a common linguistic phenomenon, evidentiality is presented by different expressions in academic papers. Our study takes the international journal SCI research papers as the research object, and examines how evidentials are used in the academic papers of Chinese and western authors in the field of Electrical and Electronic Engineering which is a very practical and typical field of scientific research. The study found that evidentials are quite universal in research articles.

From the perspective of evidential pattern, the frequency of reporting and inferring evidentials in the research papers of Chinese and western authors is much higher than that of sensory and belief evidentials. This may be due to the limitation of the discipline paradigm. As a typical representative of natural sciences, the discipline of Electrical and Electronic Engineering is still featured by quantitative analysis, formulas and data description. However, it is worth noting that English authors are far more sensitive to sensory and belief evidentials than Chinese authors, which is attributed to cultural background. Besides, they pay more attention to the interaction with readers.

The four kinds of evidentials have their own distribution features in academic papers of different countries. In the two types of sensory evidentials, Chinese authors prefer the passive verb seen, while English authors choose the active form see. In terms of belief evidentials, the grammatical forms applied by westerners is much richer than that of Chinese authors. As to inferring evidentials, modal verbs occupy the majority. The largest proportion is taken up by reporting verbs in reporting evidentials. The above research results show that commonality and difference of evidentials coexist in Chinese and western authors' research articles.

The English academic papers written by Chinese scholars can be published in the internationally renowned journal SCI, which indicates that to some degree their paper writing norms have been recognized by the academic community. However, no doubt, there is still more research in the use of evidentiality from both cultural and linguistic aspects.

\section{REFERENCES}

1. Anderson, L. B. (1986). Evidentials, paths of change, and mental maps: Typologically regular asymmetries // Chafe. W., Nichols, J. Evidentiality: The linguistic coding of epistemology. NJ: Albex, 73-312.

2. Aikhenvald, A. Y. (2003). Evidentiality in typological perspective // A. Y. Aikhenvald \& R. M. W. Dixon. Studies in Evidentiality. Amsterdam: John Benjamins, 33-62.

3. Aikhenvald, A. Y. (2004). Evidentiality. Oxford: 
Oxford University Press.

4. Chafe, W., \& Nichols, J. (1986). Evidentiality: The linguistic coding of epistemology // Norwood, N J: Ablex Publishing Corporation.

5. Dendale, P., \& Tasmowski, L. (2001). Introduction: Evidentiality and related notions. Journal of Pragmatics, (33), 339-348.

6. Fang, H. M. (2005). Research on the systemic function of evidentiality. Fudan University.

7. Fang, H. M. (2006). Review of evidentiality research. Modern Foreign Languages, (2), 191196.

8. Guan, Q. (2017). Evidentiality and Author identity Construction in English Academic Papers. Hubei University of Technology.

9. Hu, Z. L. (1994). Evidentiality of language. Foreign Language Teaching and Research, (1), 915.

10. Liu, S. H., \& Xu, J. F. (2017). Corpus-based research on the multi-disciplinary academic papers of Chinese scholars. Foreign Language and Foreign Language Teaching, (6), 61-70+147.

11. Niu, B. Y. (2005). Foreign research on evidentiality theory. Contemporary Linguistics, (1), 53-61+94.

12. Ran, Y., \& Liu, C. Y. (2019). Evidentiality in Ivanka's and Chelsea's convention speeches and its discursive power. Journal of University of Science and Technology Beijing (Social Sciences Edition), 35(1), 30-37.

13. Sun, Z. H., \& Chen, Y. (2018). Research on evidentiality of college students' English essay writing. Journal of Southwest Jiaotong University, 26(2), 18-23.

14. Wang, L., Wu, H., \& Lawrence, J. (2017). International academic English writing research (1990-2015): A scientometric analysis with Cite Space. Foreign Language Learning Theory and Practice, (4), 57-63.
15. Wang, R. J., \& Liu, J. X. (2018). A Crosslinguistic study of epistemic stance strategies in journalistic discourse in English and Chinese. Shandong Foreign Language Teaching, 39(4), 1929.

16. Wang, S. W. (2016). Evidentiality of Chinese and American Master's Thesis. Contemporary Foreign Languages Stuies, (2), 21-27.

17. Willett, T. (1988). A cross-linguistic survey of the grammaticalization of evidentiality. Studies in Language, (12), 51-97.

18. Wood, A. (2001). International scientific English language of research scientists around the [A]. In Flowerdew, J., \& Peacock, M. (eds.) Research Perspecrives on English for Academic Purposes [C]. Cambridge: Cambridge University Press, 7183.

19. Xu, W., \& Gong, J. (2014). Empirical study on the use of evidentiality in second language academic writing. Journal of PLA Foreign Languages University, (4), 12-22.

20. Yang, L. X. (2009). Evidentiality in English research articles. Xiamen University.

21. Yang, L. X. (2013). Review of evidential studies in China: status and prospects. Journal of Shanxi University (Philosophy \& Social Science), 36(6), 64-68.

22. Yang, L. X. (2015). Author identity construction in English academic articles: a perspective of evidentiality. Foreign Language Teaching, 36(2), 21-25.

23. Yu, B. F. (2015). Evidentiality and interpersonal significance of interdisciplinary doctoral dissertation abstracts. Studies in Contemporary Foreign Languages, (4), 29-36+77.

24. Zhao, G. X. (2017). Research on evidentiality of English and Chinese academic articles and author identity construction. Qufu Normal University. 